Supplement of Biogeosciences, 13, 5333-5355, 2016

http://www.biogeosciences.net/13/5333/2016/

doi:10.5194/bg-13-5333-2016-supplement

(C) Author(s) 2016. CC Attribution 3.0 License.

(c) (i)

Supplement of

\title{
Anaerobic oxidation of methane alters sediment records of sulfur, iron and phosphorus in the Black Sea
}

Matthias Egger et al.

Correspondence to: Matthias Egger (m.j.egger@uu.nl)

The copyright of individual parts of the supplement might differ from the CC-BY 3.0 licence. 


\section{Multicomponent model formulation}

2 Molecular diffusion coefficients $D_{m}\left(\mathrm{~cm}^{2} \mathrm{yr}^{-1}\right)$ were corrected for tortuosity in the porous medium according to 3 Boudreau (1996).

$$
D^{\prime}=\frac{D_{m}}{1-2 \ln (\phi)}
$$

4 To account for sediment compaction, a depth-dependent porosity $(\phi)$ was described by

$$
\phi(x)=\phi_{\infty}+\left(\phi_{0}-\phi_{\infty}\right) e^{-\frac{x}{\gamma}}
$$

5 where $x$ is the distance from the sediment-water interface $(\mathrm{cm}), \phi_{\infty}$ the porosity at depth in the sediment, $\phi_{0}$ the 6 porosity at the sediment surface, and $\gamma$ the porosity attenuation factor (see Fig. S1 and Table S1).

$7 \quad$ The advective velocity of solids at depth $v_{\infty}$ was described by

$$
v_{\infty}=\frac{F_{\text {sed }}}{\rho\left(1-\phi_{\infty}\right)}
$$

8 where $F_{\text {sed }}$ denotes the sediment accumulation rate $\left(\mathrm{g} \mathrm{cm}^{-2} \mathrm{yr}^{-1}\right)$ and $\rho$ the sediment density (Meysman et al., 2005). 
11 Table S1. Environmental parameters used by the diagenetic model.

\begin{tabular}{|c|c|c|c|}
\hline Parameter & Symbol & Value & Units \\
\hline Porosity at surface & $\phi_{0}$ & 0.97 & - \\
\hline Porosity at depth & $\phi_{\infty}$ & 0.61 & - \\
\hline Porosity e-folding distance & $\gamma$ & 95 & $\mathrm{~cm}$ \\
\hline Sediment density & $\rho$ & 2.31 & $\mathrm{~g} \mathrm{~cm}^{-3}$ \\
\hline Temperature & $\mathrm{T}$ & 1 & ${ }^{\circ} \mathrm{C}$ \\
\hline Bottom water $\mathrm{Cl}^{-}$concentration ${ }^{*}$ & {$\left[\mathrm{Cl}^{-}\right]_{0}$} & $\frac{\text { salinity }}{1.80655 * M_{C l^{-} * \rho_{S W}}}$ & $\mathrm{~mol} \mathrm{~cm}{ }^{-3}$ \\
\hline Bottom water $\mathrm{SO}_{4}{ }^{2-}$ concentration ${ }^{*}$ & {$\left[\mathrm{SO}_{4}{ }^{2-}\right]_{0}$} & $\frac{0.14 * \text { salinity }}{1.80655 * M_{S O_{4}^{2-*}} \rho_{S W}}$ & $\mathrm{~mol} \mathrm{~cm}{ }^{-3}$ \\
\hline $\mathrm{C}: \mathrm{N}$ ratio of organic matter & $\mathrm{C} / \mathrm{N}$ & 6.625 & - \\
\hline $\mathrm{C}: \mathrm{P}$ ratio of organic matter & $\mathrm{C} / \mathrm{P}$ & 106 & - \\
\hline $\mathrm{C}: \mathrm{P}$ ratio of organic matter under anoxia & $\mathrm{C} / \mathrm{P}_{\text {anoxic }}$ & 424 & \\
\hline $\mathrm{P}: \mathrm{Fe}$ ratio for $\mathrm{Fe}(\mathrm{OH})_{3}{ }^{\alpha}$ & $\chi^{\alpha}$ & 0.1 & - \\
\hline $\mathrm{P}: \mathrm{Fe}$ ratio for $\mathrm{Fe}(\mathrm{OH})_{3}{ }^{\beta}$ & $\chi^{\beta}$ & 0.055 & - \\
\hline $\mathrm{P}: \mathrm{Fe}$ ratio for $\mathrm{Fe}(\mathrm{OH})_{3}^{\gamma}$ & $\chi^{\gamma}$ & 0.03 & - \\
\hline
\end{tabular}

$12 \mathrm{M}_{\mathrm{Cl}^{-}}$and $\mathrm{M}_{\mathrm{SO}_{4}^{2-}}$ denote the molecular weights of $\mathrm{Cl}^{-}$and $\mathrm{SO}_{4}{ }^{2-} ; \rho_{\mathrm{SW}}$ is the seawater density calculated for the in-situ salinity,

13 temperature and pressure.

14 


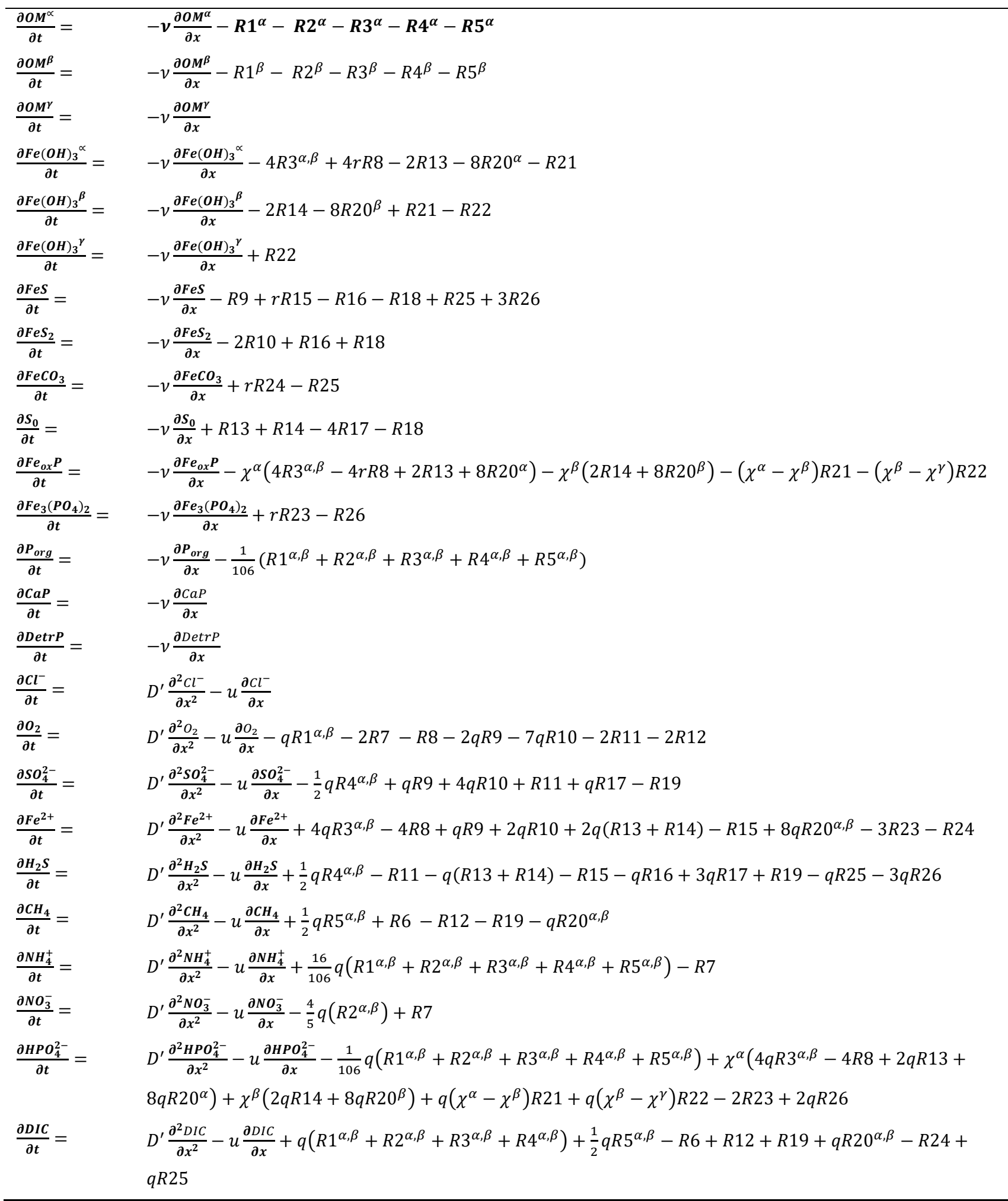


19 Table S3. Time-dependent boundary conditions at the sediment surface.

\begin{tabular}{|c|c|c|c|}
\hline Parameter & $t>9000$ yrs B.P. & $9000>t>7600 y r s$ B.P. & $t<7600$ yrs B.P \\
\hline $\mathrm{J}_{\mathrm{FeCO}_{3}}$ & 3.81 & 1.14 & 1.14 \\
\hline$J_{S_{0}}$ & 0 & 0 & 0 \\
\hline$J_{\text {CaP }}$ & 0.18 & 0.18 & 0.18 \\
\hline$J_{\text {DetrP }}$ & 0.32 & 0.095 & 0.095 \\
\hline$\left[\mathrm{O}_{2}\right]$ & 0.18 & 0.18 & 0 \\
\hline$\left[\mathrm{Fe}^{2+}\right]$ & 0 & 0 & 0 \\
\hline$\left[\sum \mathrm{H}_{2} \boldsymbol{S}\right]$ & 0 & 0 & 0.08 \\
\hline$\left[\mathrm{CH}_{4}\right]$ & 0 & 0 & 0 \\
\hline$\left[\sum \mathbf{N H}_{4}^{+}\right]$ & 0 & 0 & 0 \\
\hline$\left[\mathrm{NO}_{3}^{-}\right]$ & 0 & 0 & 0 \\
\hline$\left[\mathrm{HPO}_{4}^{2-}\right]$ & 0 & 0 & 0 \\
\hline$[D I C]$ & 3 & 3 & 3 \\
\hline
\end{tabular}

21 


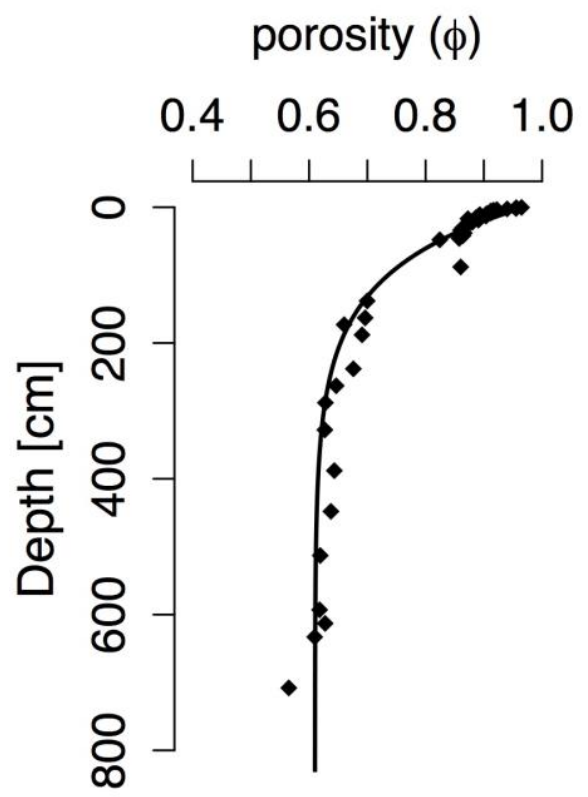

24 Figure S1. Porosity measurements (black diamonds) and modeled porosity profile (black line) at site 4. 

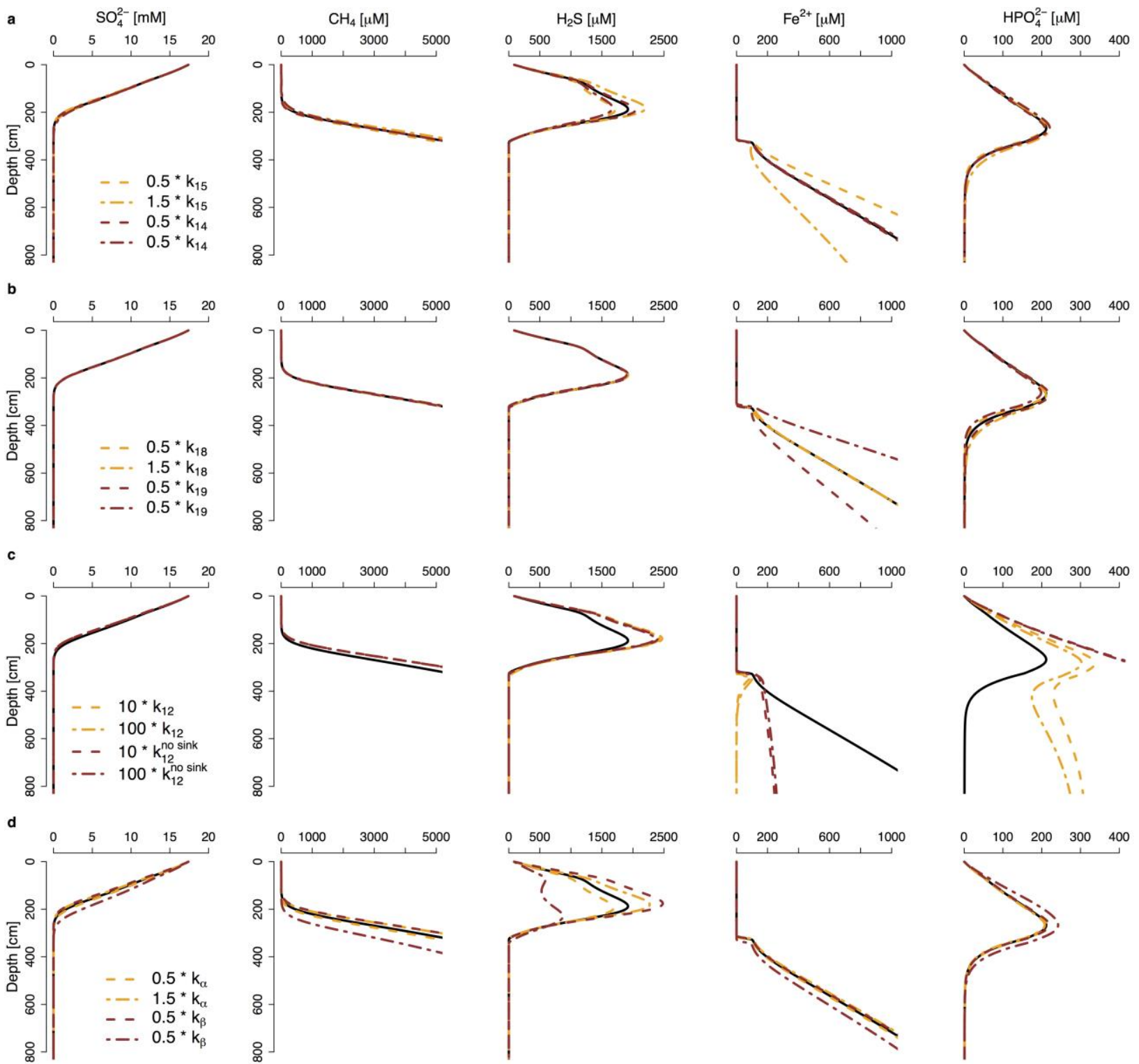

Figure S2. Sensitivity of modeled pore water profiles to changes in key parameters (see Table 4 and 5 for reaction equations and $k$ values). The solid black lines represent the standard model run. (a) $\pm 50 \%$ change in the rate constant for Fe-AOM $\left(k_{15}\right.$, orange) and $\mathrm{SO}_{4}-\mathrm{AOM}\left(\mathrm{k}_{14}\right.$, brown). Note that the relative contribution of Fe-AOM to total AOM (i.e. Sum of $\mathrm{Fe}-\mathrm{AOM}$ and $\mathrm{SO}_{4}$-AOM) varies between 0.4 to $0.9 \%$ for the parameter range considered here. (b) $\pm 50 \%$ change in vivianite $\left(k_{18}\right.$, orange) and Fe carbonate $\left(k_{19}\right.$, brown) formation rate constants. (c) 10 fold and 100 fold increase in $S_{0}$ disproportionation rate constant $\left(\mathrm{k}_{12}\right)$ and its effect on pore water profiles with (orange) and without (brown) sinks for

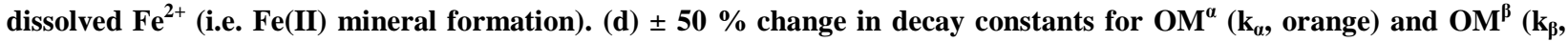
brown). In general, modeled profiles of sulfide, $\mathrm{Fe}^{2+}$ and $\mathrm{HPO}_{4}{ }^{2-}$ show the highest sensitivity to the parameterization used. 


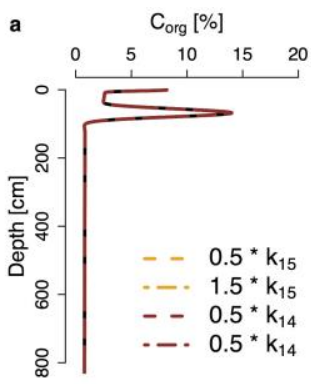

b
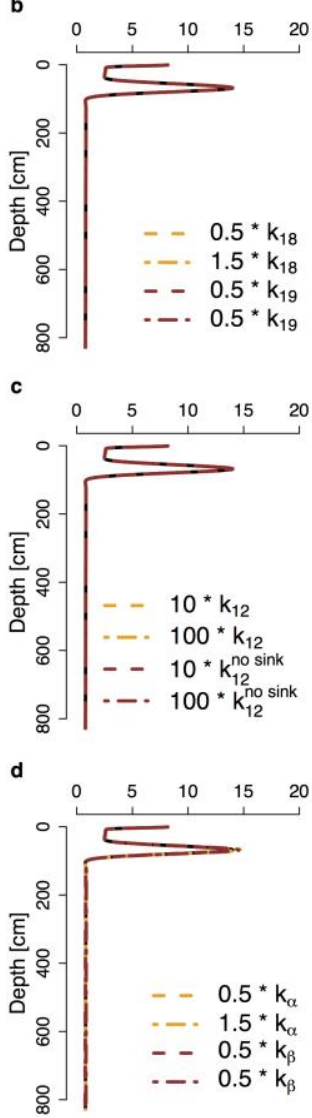
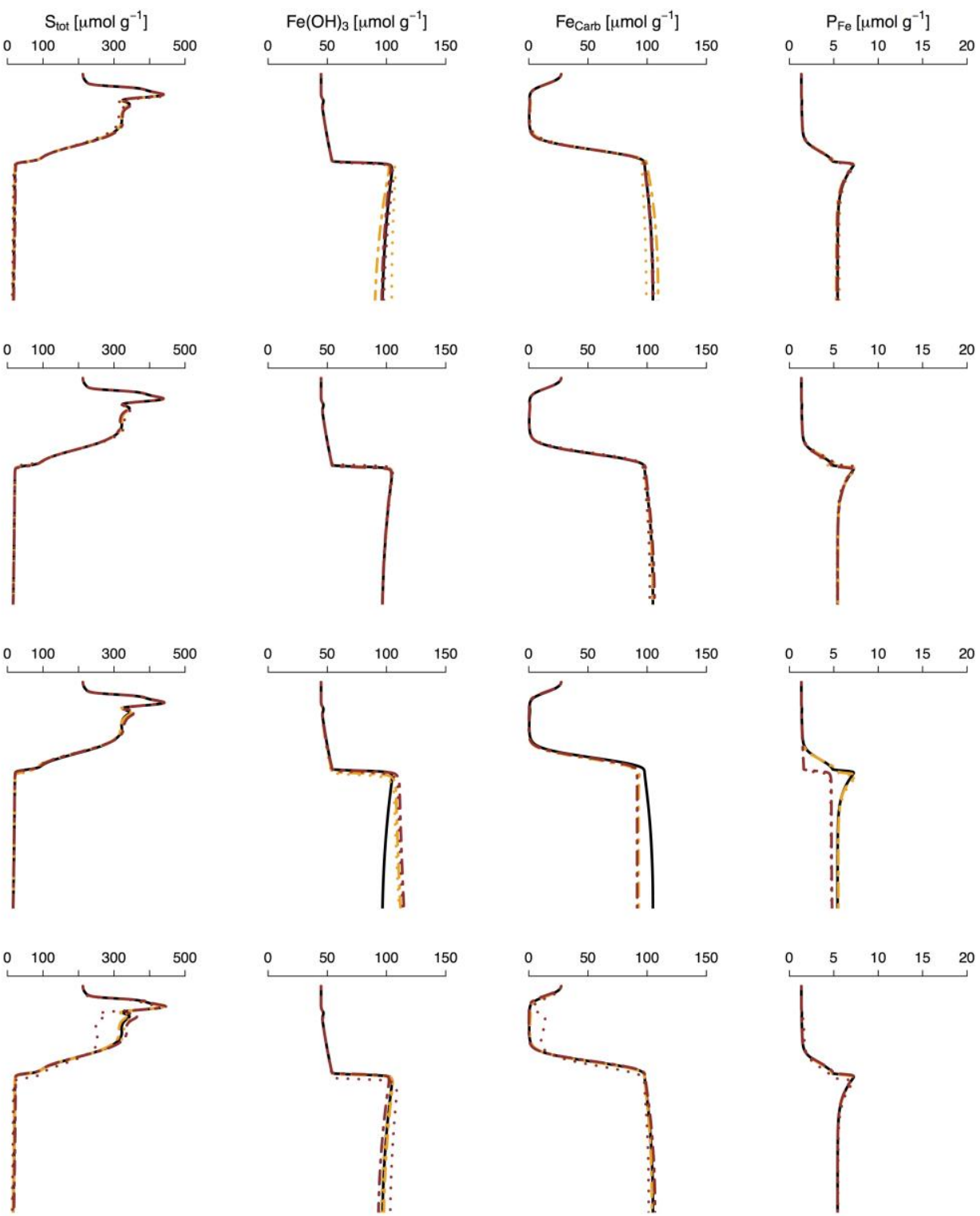

Figure S3. Sensitivity of modeled solid phase profiles to changes in key parameters (see Table 4 and 5 for reaction equations and $k$ values). The solid black lines represent the standard model run. (a) $\pm 50 \%$ change in the rate constant for

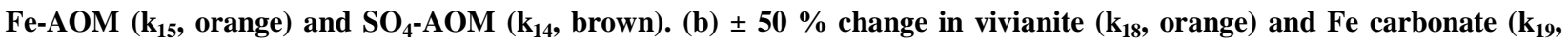
brown) formation rate constants. (c) 10 fold and 100 fold increase in $S_{0}$ disproportionation rate constant $\left(k_{12}\right)$ and its effect on pore water profiles with (orange) and without (brown) sinks for dissolved $\mathrm{Fe}^{2+}$ (i.e. $\mathrm{Fe}$ (II) mineral formation). (d) \pm 50 $\%$ change in decay constants for $O M^{\alpha}\left(k_{\alpha}\right.$, orange) and $O M^{\beta}\left(k_{\beta}\right.$, brown). Note that the solid phase results are not very sensitive to the parameterization used. 

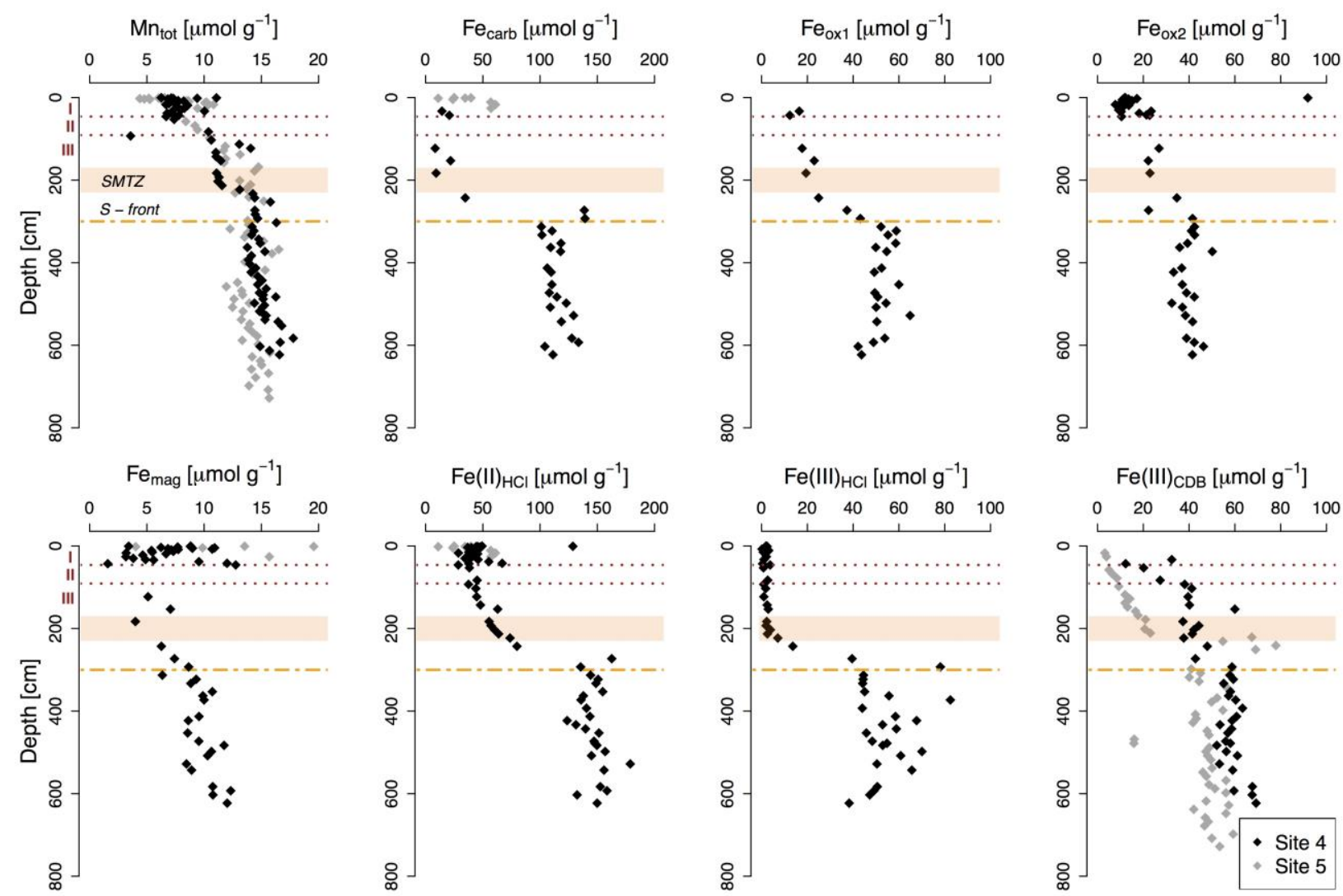

Figure S4. Solid phase profile of total sedimentary Mn and Fe extraction results for site 4 (black diamonds) and 5 (grey diamonds). See Table 1 for a description of the different $F e$ phases. Note that $\mathrm{Fe}_{\text {carb }}$ is not corrected for dissolution of AVS during the $\mathrm{Na}$ acetate extraction step. $\mathrm{Fe}(\mathrm{III})_{\mathrm{CDB}}$ for site 5 represents the amount of Fe extracted during the CDB-step of the SEDEX P extraction. Red dotted lines and roman numbers indicate the transitions between the lithological Unit I (modern coccolith ooze), Unit II (marine sapropel) and Unit III (limnic deposits). The orange bar represents the sulfatemethane transition zone (SMTZ) and the orange dashed line shows the current position of the downward migrating sulfidization front (S-front). 

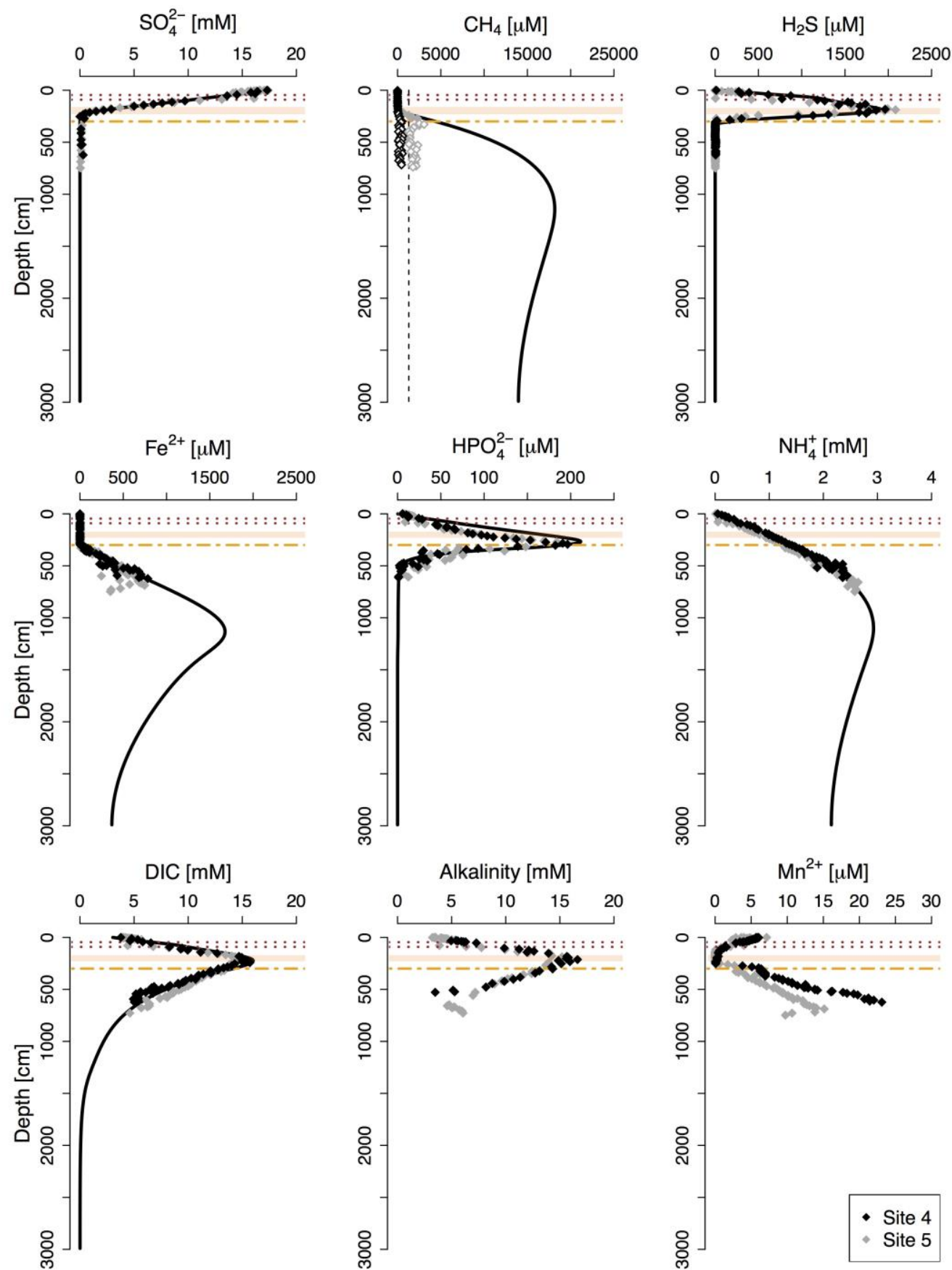

Figure S5. Pore water profiles (whole model domain, i.e. $3000 \mathrm{~cm}$ ) for site 4 (black diamonds) and 5 (grey diamonds). Black lines represent profiles derived from the diagenetic model. Red dotted lines indicate the transitions between the lithological Unit I (modern coccolith ooze), Unit II (marine sapropel) and Unit III (limnic deposits). The orange bar represents the sulfate-methane transition zone (SMTZ) and the orange dashed line shows the current position of the downward migrating sulfidization front. The dashed vertical line indicates the $\mathrm{CH}_{4}$ saturation concentration at atmospheric pressure (Mogollón et al., 2013). The open diamonds indicate $\mathrm{CH}_{4}$ concentrations that are likely underestimated due to outgassing of $\mathrm{CH}_{4}$ during coring. 

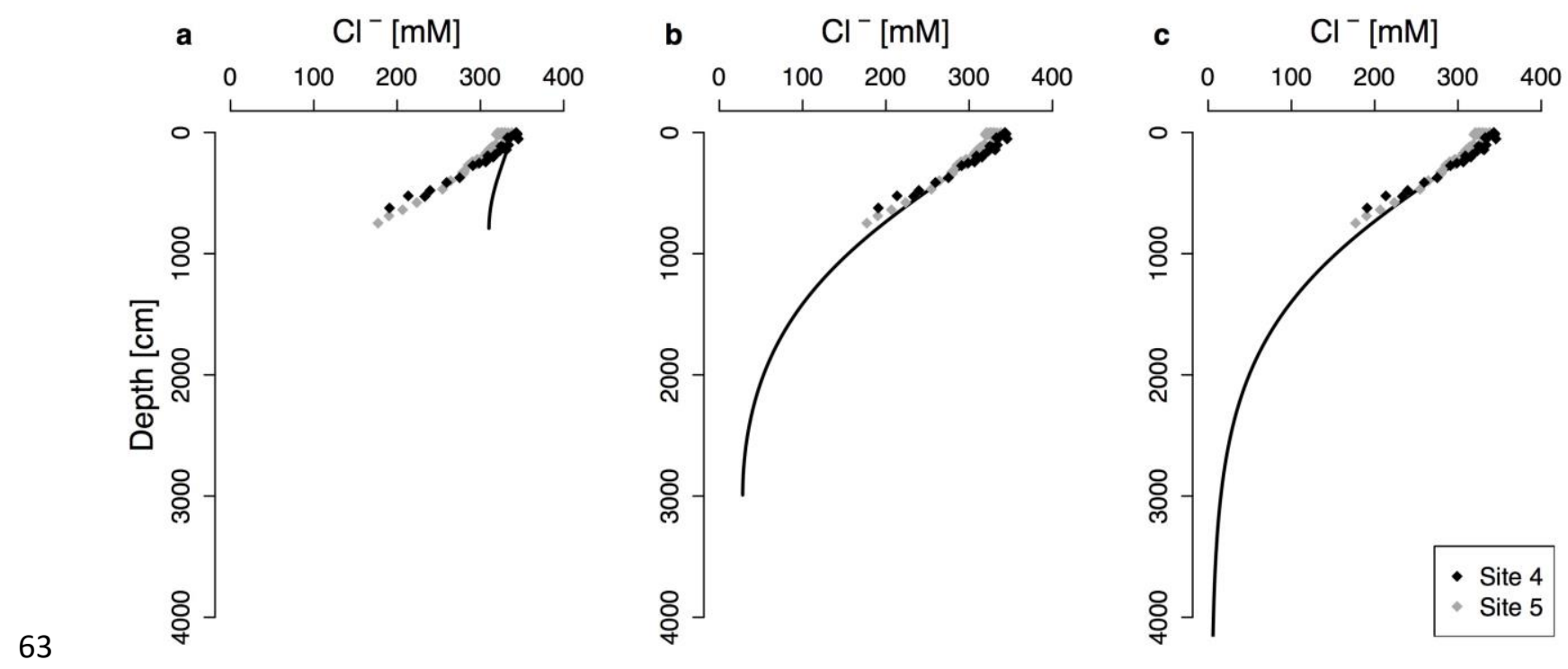

64 Figure S6. The influence of a zero gradient boundary condition at the base of the model domain on the pore water profile 65 of chloride $\left(\mathrm{Cl}^{-}\right)$is dependent on the modeled sediment depth. (a) Due to the transient diagenesis, a zero gradient is not 66 reached within the depth range of the available data, i.e. the upper $800 \mathrm{~cm}$. (b) A model length of $3000 \mathrm{~cm}$ results in a good 67 fit of the modeled $\mathrm{Cl}^{-}$profile with the measured pore water concentrations. Expanding the model domain to $4000 \mathrm{~cm}$ (c) 68 largely increases the modeling time, with no significant improvement of the model fit. Thus, a depth range of $3000 \mathrm{~cm}$ was 69 chosen in this study. The solid lines represent model simulations assuming an initial salinity of 1 for the freshwater phase and a linear increase to a salinity of 22 between 8500 and 1500 years ago, after which salinity stays constant. 

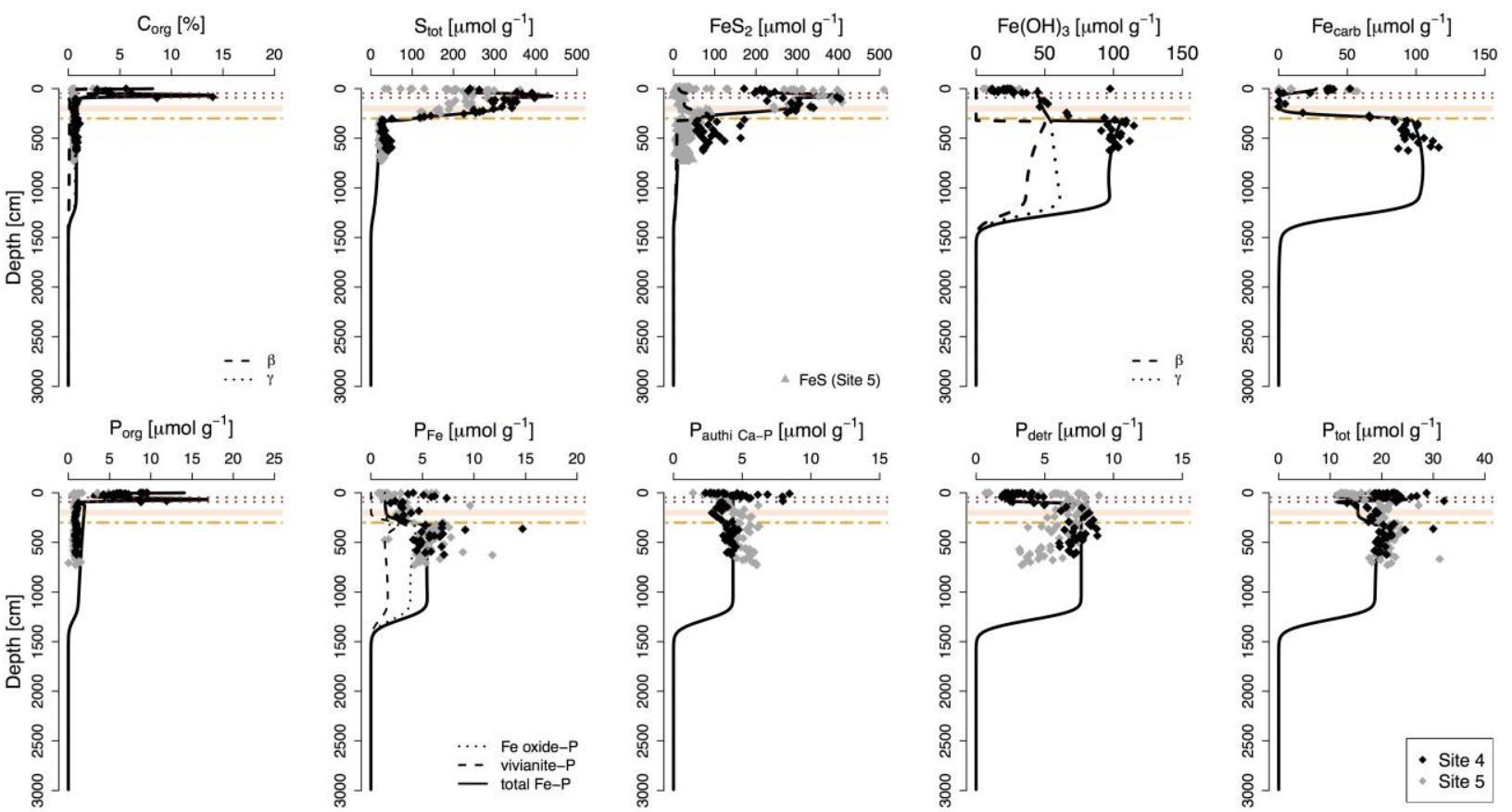

Figure S7. Solid phase profiles (whole model domain, i.e. $3000 \mathrm{~cm}$ ) for site 4 (black diamonds) and 5 (grey diamonds).

$\mathrm{Fe}_{\text {carb }}$ was corrected for apparent AVS dissolution during the $\mathrm{Na}$ acetate extraction step (the uncorrected $\mathrm{Fe}_{\text {carb }}$ data is

given in Fig. S4). Black lines represent profiles derived from the diagenetic model. Red dotted lines indicate the transitions

between the lithological Unit I (modern coccolith ooze), Unit II (marine sapropel) and Unit III (limnic deposits). The orange bar represents the sulfate-methane transition zone (SMTZ) and the orange dashed line shows the current position of the downward migrating sulfidization front.

\section{Supplementary references}

Boudreau, B. P.: The diffusive tortuosity of fine-grained unlithified sediments, Geochim. Cosmochim. Acta, 60(16), 3139-3142, doi:10.1016/0016-7037(96)00158-5, 1996. 2005.

87 Mogollón, J. M., Dale, A. W., Jensen, J. B., Schlüter, M. and Regnier, P.: A method for the calculation of anaerobic 